Article

\title{
Quinone-Based Polymers for Label-Free and Reagentless Electrochemical Immunosensors: Application to Proteins, Antibodies and Pesticides Detection
}

\author{
Benoit Piro ${ }^{1, *}$, Steeve Reisberg ${ }^{1}$, Guillaume Anquetin ${ }^{1}$, Huynh-Thien Duc ${ }^{2}$ and \\ Minh-Chau Pham ${ }^{1}$
}

1 Université Paris Diderot, Sorbonne Paris Cité, ITODYS, UMR 7086 CNRS, 15 rue J-A de Baïf, 75205 Paris Cedex 13, France; E-Mails: steeve.reisberg@univ-paris-diderot.fr (S.R.); guillaume.anquetin@univ-paris-diderot.fr (G.A.); mcpham@univ-paris-diderot.fr (M.-C.P.)

2 Université Paris XI, INSERM U-1014, Groupe Hospitalier Paul Brousse-94800 Villejuif, France; E-Mail: guy.duc@inserm.fr

* Author to whom correspondence should be addressed; E-Mail: piro@ univ-paris-diderot.fr; Tel.: +33-1-57-27-72-24.

Received: 14 November 2012; in revised form: 24 December 2012 / Accepted: 10 January 2013 / Published: 14 January 2013

\begin{abstract}
Polyquinone derivatives are widely recognized in the literature for their remarkable properties, their biocompatibility, simple synthesis, and easy bio-functionalization. We have shown that polyquinones present very stable electroactivity in neutral aqueous medium within the cathodic potential domain avoiding side oxidation of interfering species. Besides, they can act as immobilized redox transducers for probing biomolecular interactions in sensors. Our group has been working on devices based on such modified electrodes with a view to applications for proteins, antibodies and organic pollutants using a reagentless label-free electrochemical immunosensor format. Herein, these developments are briefly reviewed and put into perspective.
\end{abstract}

Keywords: conducting polymer; square wave voltammetry; impedance spectroscopy; immunosensor; proteins; peptides; pollutants; electrochemical biosensor; label-free detection 


\section{General Introduction}

\subsection{Generalities}

An antigen $(\mathrm{Ag})$ is a nanometer-sized molecule with molecular weight higher than 1,500 Da to which the immune system of animals responds by synthesizing antibodies ( $\mathrm{Ab}$ ) able to selectively bind the antigen. There are five primary classes of antibodies, namely $\operatorname{IgG}, \operatorname{IgM}, \operatorname{IgA}, \operatorname{IgD}$ and $\operatorname{IgE}$, but only $\mathrm{IgG}$ antibodies are used in immunosensors. Ab-Ag binding is based on non-covalent interactions and is characterized by an association constant, $\mathrm{K}_{\mathrm{a}}$, in the range $10^{5}-10^{13} \mathrm{M}$. Polyclonal $\mathrm{Ab}$ are directed to different binding sites (epitopes) on Ag, with different affinities. Monoclonal Ab, specific to only one epitope of an $\mathrm{Ag}$, are preferred. These $\mathrm{Ab}$ generally present higher affinity and specificity.

\subsection{Immunoassays}

Analytical tools using Ab-Ag couples are called immunoassays. They are capable of direct and specific detection in complex samples, due to highly specific interactions between $\mathrm{Ab}$ and $\mathrm{Ag}$. Commercially available immunoassay kits are inexpensive, simple, adapted to field use and constitute a rapid way of determining contaminants in environmental samples. Generally, the detection scheme relies on labeling with radioisotopes (radioimmunoassay, RIA, now scarcely used), chemiluminescent compounds (chemiluminescence immunoassay, CLIA) [1,2] or enzymes (enzyme immunoassay, EIA, and enzyme-linked immunosorbent assay, ELISA) [3-6]. Usually, the Ab or the Ag is immobilized on a substrate. In the most basic format, an immunocomplex (Ab-Ag) is formed upon contact with a solution containing the labeled analyte (generally the Ag). The analyte concentration in solution is then derived from that of bound analyte. In a more efficient sandwich format, $\mathrm{Ab}$ are immobilized on a substrate which is put in contact with the sample containing the Ag, then a labeled secondary antibody is added (see Figure 1(a)). Competitive formats also exist, in which competition takes place between non-labeled and labeled Ag for an immobilized Ab (Figure 1(b)).

Figure 1. Principle of enzyme-linked immunosorbent assay (ELISA). (a) Sandwich format (b) Competitive format.

3-a Sandwich ELISA

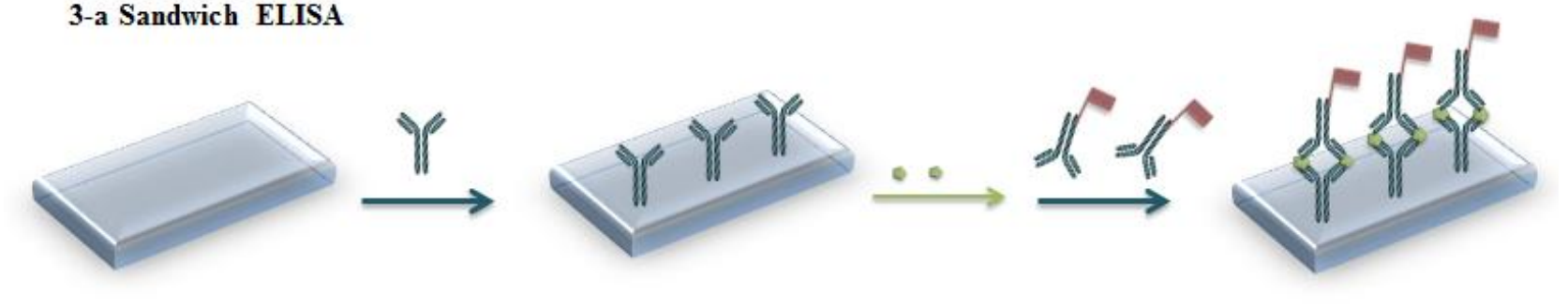

3-b Competitive ELISA

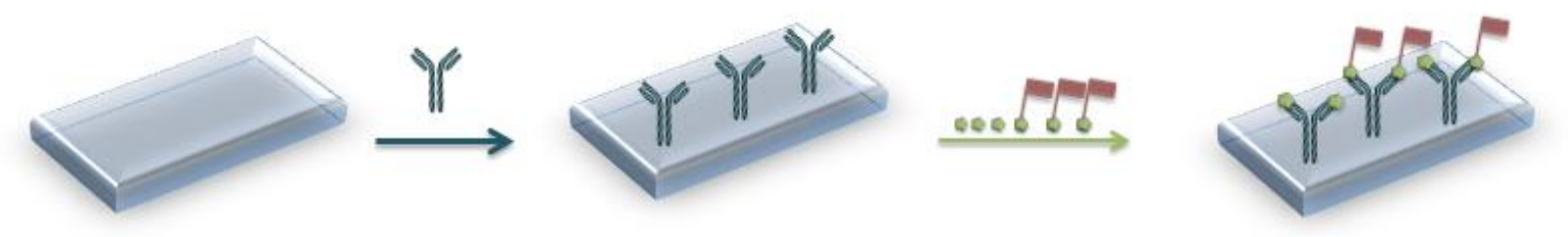




\subsection{Immunosensors}

Today, most immunoassays are performed using ELISA. They are generally performed in microtiter plates, which demand time and skilled operators. Moreover, ELISA tests are not efficient for simultaneous multiple analysis (multiplexing), continuous detection and transduction into an electronically usable signal. In the near future, biosensors using antibody-antigen complexes (called immunosensors) may provide faster and easier methods. An immunosensor consists of a sensing element (an immobilized $\mathrm{Ab}$ or $\mathrm{Ag}$ ) and a transducer which translates the biomolecular recognition event into an electrical signal. This can be performed indirectly through SPR [7,8]. However, SPR is expensive, requires specialized technicians and is rarely employed for on-site measurement. In addition, optic-based detections in general are fragile. Transduction can also be performed through piezoelectric techniques [9] or near field microscopies (AFM, SECM) [10], with few of the same inconveniences. Field-effect transistors are competitive [11,12], but we focus in this paper on electrochemical sensors which are much more widely reported in the literature.

\subsection{Electrochemical Immunosensors}

Electrochemical biosensors have attracted considerable attention due to the advantages of robustness, low cost, low power consumption, simplicity, high sensitivity, compatibility with mass manufacturing using existing micro-fabrication technologies, and portability; therefore they are excellent candidates for easy-to-use immunosensors. The most popular format uses a redox reaction from a labeled $\mathrm{Ab}$ (or $\mathrm{Ag}$ ) which provides a current proportional to the analyte concentration. For example, $\mathrm{Ab}$ or Ag may be labeled with enzymes producing an electroactive product from a reagent added in the analytical solution [13]. Detection is generally performed by cyclic voltammetry, chronoamperometry or most frequently, impedimetry [14]. However, it would be more interesting to perform electrochemical transduction without labeling the biomolecules by a redox tag or adding redox reagent to the solution. This can be performed with conducting polymers (ECPs).

\subsection{Electrochemical Immunosensors Based on Conducting Polymers}

ECPs are smart materials because they present at the same time, grafting, coupling and transduction abilities [15-18] without help of a supplementary redox label put on the Ab or in solution. As Ab-Ag complexes are heavy and hindering, it is expected that their presence in the vicinity of the polymer/solution interface strongly influences ion diffusion from the solution to the polymer/solution interface and mixed charge transport inside the film. This typically leads to a measurable decrease in the electroactivity of the underlying conducting polymer.

\subsubsection{Polypyrrole}

The most popular ECP for biosensing applications is polypyrrole (PPy) [19-21]. In 1991, John et al. [22] described a method for incorporation of antibodies (anti-HSA) in PPy. It was shown by cyclic voltammetry that HSA (human serum albumin) interacted with the electrode surface while no response was obtained with pure PPy. Sadik and Wallace [23] optimized this method with detection limits in the order of $\mathrm{nM}$ [24]. Later, based on the same principle, an electrochemical immunosensor 
for direct detection of small organic antigenic pollutants like pesticides or antibiotics was developed. For example, polychlorinated biphenyls (PCBs) have been detected in water with a detection limit of $0.05 \mu \mathrm{g} \cdot \mathrm{L}^{-1}[25-28]$.

\subsubsection{Other ECPs}

Other conducting polymers were also used for detection of pollutants. For example, Shim et al. [29] fabricated a label free impedimetric immunosensor to detect bisphenol A (endocrine disrupting compounds released into the environment from many kinds of polycarbonate plastics, epoxy resins of food cans, etc.) using polythiophene, with a detection limit of $0.3 \pm 0.07 \mathrm{ng} \cdot \mathrm{mL}^{-1}$. Khan et al. [30] performed an impedimetric immunosensor based on a chitosan/polyaniline hybrid to detect ochratoxin-A (a mycotoxin found in food products, human blood, breast milk, tissues and organs of animals). Other polymers were also used, and more particularly polyquinones, which present particular redox properties. For example, a series of aminonaphthoquinones and aminoanthraquinones were originally developed in the 80 's and 90's for electrocatalytic purposes or energy storage [31-37]. More recently, other polyquinone films were developed to be used as transducers in biosensors [38,39]. Indeed, even if polyquinone derivatives have been much less investigated than other ECPs, they present good biocompatibility, easy bio-functionalization and remarkably stable electroactivity in neutral aqueous medium [40]. These properties can be used to probe biomolecular interactions [41-44] due to the high sensitivity of the quinone group to changes in its local physico-chemical environment [45-47].

\section{Recent Advances on Polyquinone-Modified Electrodes for Immunosensing}

\subsection{General Approach}

\subsubsection{Principles}

The major bottleneck is how to achieve direct electrochemical transduction when there is no intrinsic charge transfer reaction following molecular recognition. The most original and innovative idea is to directly immobilize the redox transducer on the sensor surface so that its electroactivity can be influenced by steric hindrance of heavy molecules (Ab or proteins) in its neighborhood. The detection of the target is performed simply by recording the redox current before and after recognition. This approach allows the development of easy-to-use, reagentless and label-free electrochemical devices. Several sensing architectures could be designed for such an approach, schematized and summarized in Figure 2 below.

Cases a-c, Figure 2, describe the most common approaches, which use relatively bulky probes. In order to reduce the size of the grafted probe, it is also possible to use peptides, as shown for cases d,e. Finally, small organic molecules may be used (f) instead of proteins or peptides [48]. 
Figure 2. Classical formats used for detections of proteins or antibodies. (a) Grafted antibodies ( $\mathrm{Ab}$ ) to detect proteins; (b) Grafted antibody fragment $\mathrm{F}(\mathrm{ab}$ ') to detect proteins; (c) Grafted protein to detect Ab. Use of peptides to detect (d) antibodies or (e) proteins. (f) Use of small organic molecules.
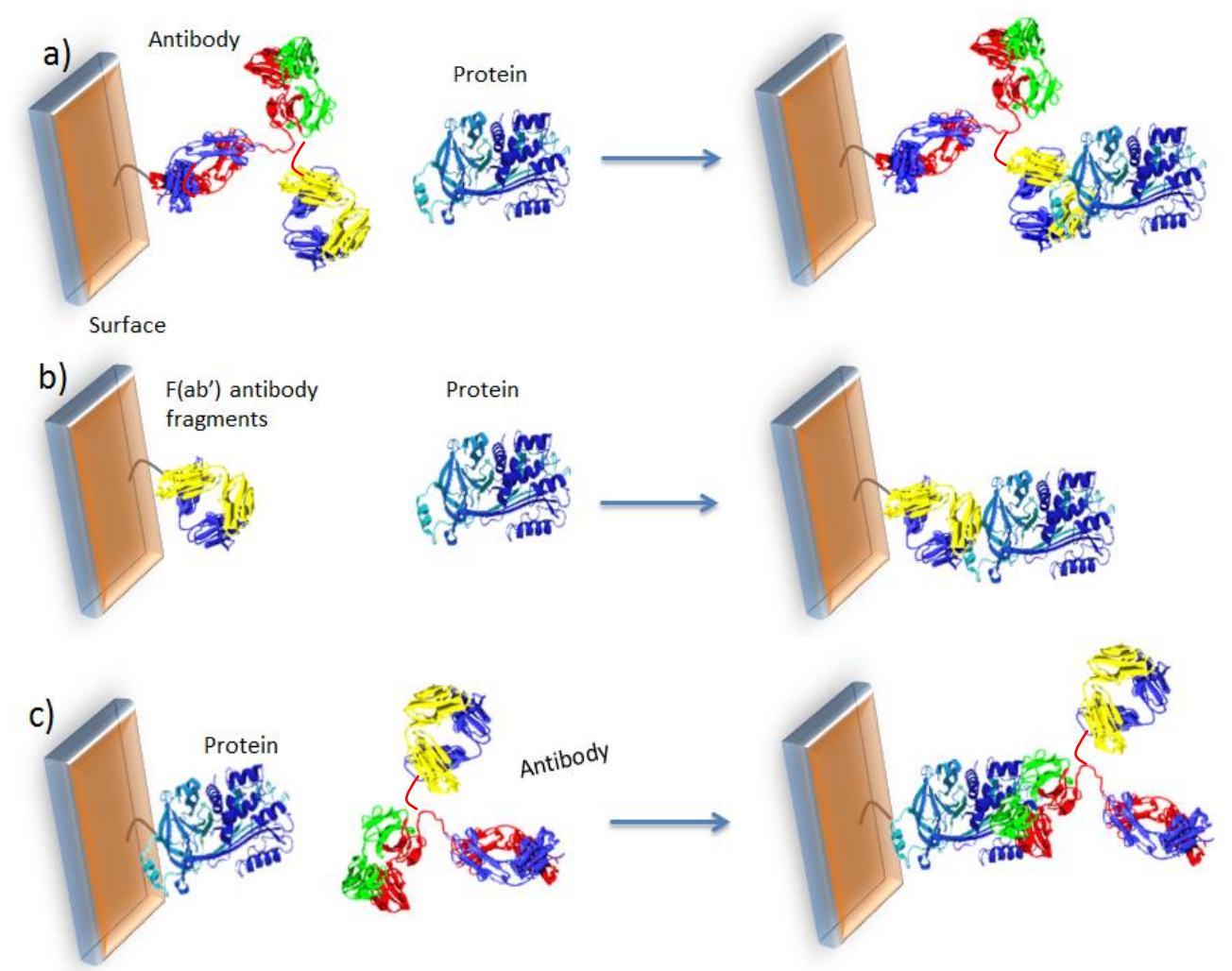

d)
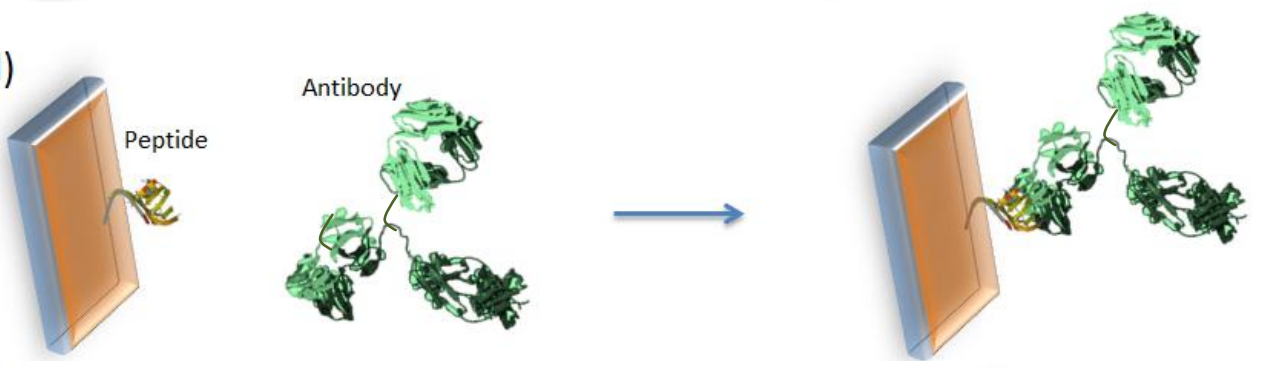

e)
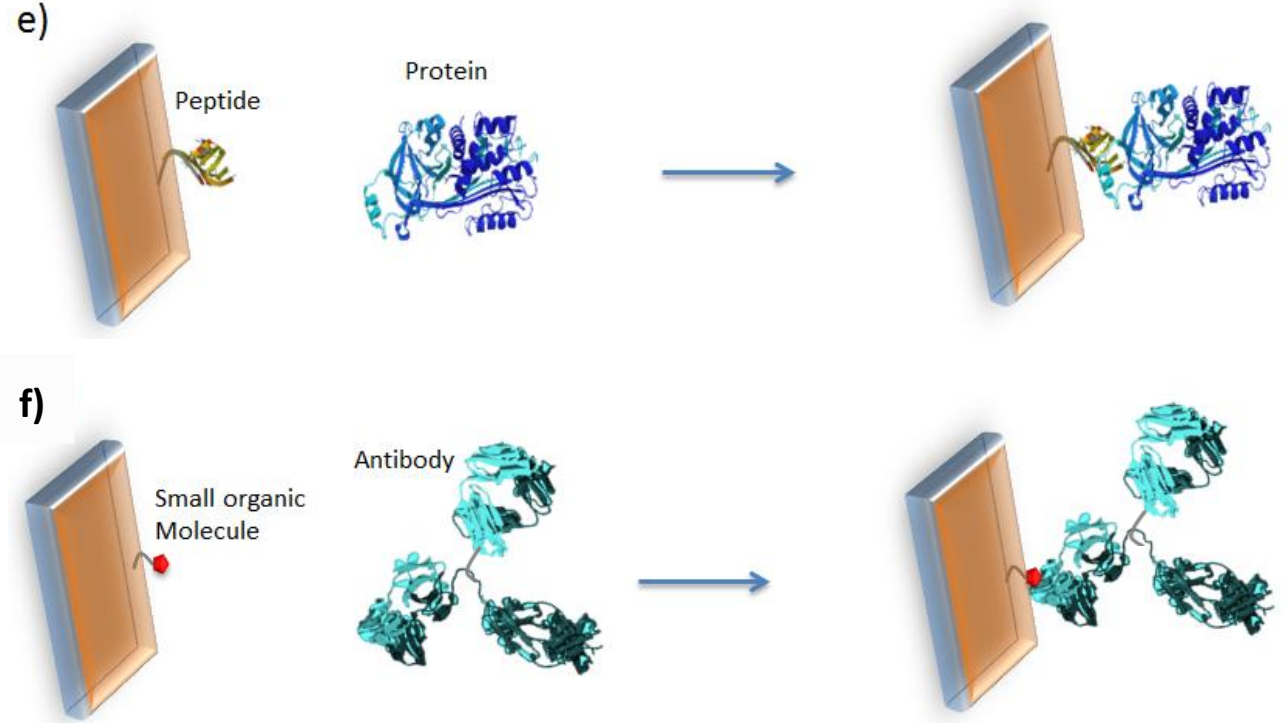


\subsubsection{Design}

Because the sensor's architecture must be adaptable to any format from among those schematized in Figure 2, it has to be engineered from "elemental bricks" joined together to form the whole electrochemical sensor, namely the grafting group, the redox transducer and the probe able to selectively complex the target molecule. This construction is schematized in Figure 3 below.

Figure 3. Schematic view of the "elemental bricks" needed to construct a versatile reagentless and label-free electrochemical sensor.

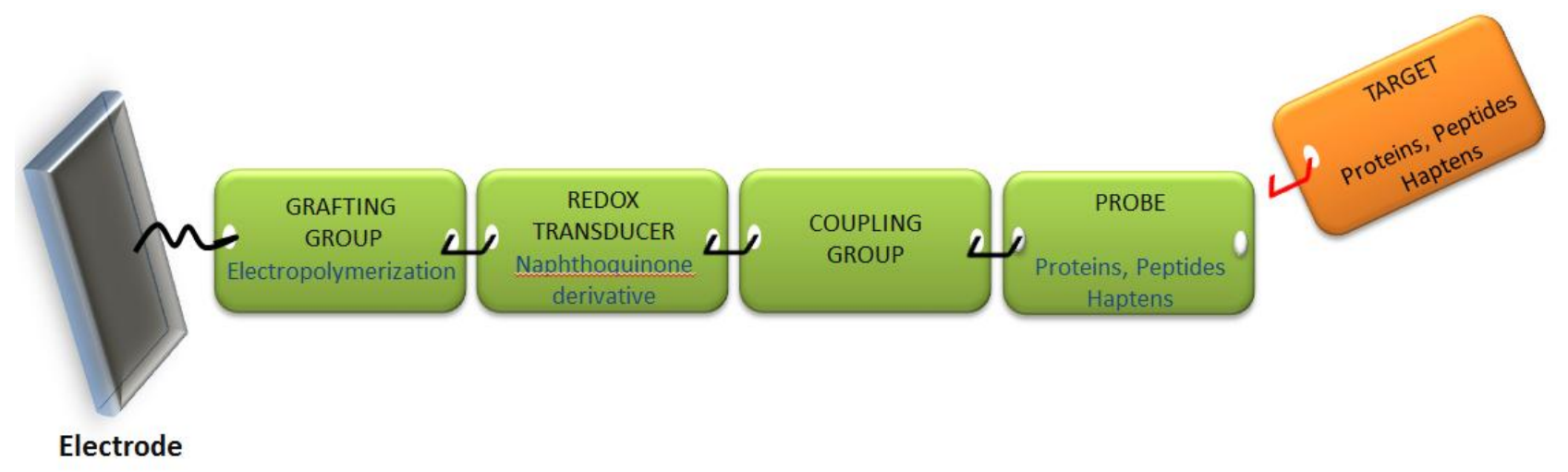

We selected electropolymerization as the strategy to graft the sensing material, using hydroxynaphthoquinone monomers, which polymerize by electrooxidation of the hydroxyl group. The quinone plays the role of redox transducer, and we developed a coupling strategy to directly graft a spacer (e.g., an alkyl chain bearing a functional group) on the $\alpha$-carbon of the quinone. This spacer is then used to couple the probe (antibody, protein, peptide or modified hapten).

We first synthesized 5-hydroxy-2-thioacetic acid-1,4-naphthoquinone.(HSNQA) (Figure 4(a)). The reaction of thiols with various hydroxynaphthoquinone derivatives leads, in one step, to substituted quinone rings, under mild conditions [49]. Another spacer was also designed by straightforward carbon-carbon coupling, leading to 5-hydroxy-1,4-naphthoquinone-3-propionic acid (HNQA) (Figure 4(b)) [42].

Figure 4. (a) Structure of 5-hydroxy-2-thioacetic acid-1,4-naphthoquinone) (HSNQA) and (b) 5-hydroxy-1,4-naphthoquinone-3-propionic acid (HNQA).

(a)

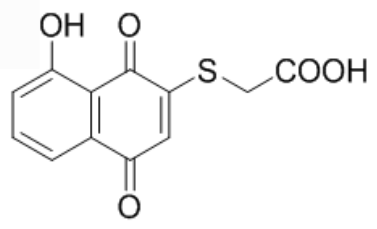

(b)<smiles>O=C(O)CCC1=CC(=O)c2cccc(O)c2C1=O</smiles>

We obtained a multifunctional conjugated copolymer poly(5-hydroxy-1,4-naphthoquinone-co-(5hydroxy-2-thioacetic acid-1,4-naphthoquinone), poly(HNQ-co-HSNQA) and used it as the immobilizing and transducing element for a label-free electrochemical immunosensor [44]. Biomolecules can be coupled through peptide links between the $-\mathrm{COOH}$ group and the terminal $-\mathrm{NH}_{2}$ group on the bioprobe. The quinone group was used for its redox properties. It is well known that the quinone/hydroquinone 
system presents an electroactivity which is sensitive to its local environment, particularly cations, protons or sodium ions in aqueous solution. The redox reaction in the film involves the reaction $\mathrm{Q}+2 \mathrm{H}^{+}+2 \mathrm{e}^{-} \rightleftharpoons \mathrm{QH}_{2}$ or $\mathrm{Q}+2 \mathrm{Na}^{+}+2 \mathrm{e}^{-} \rightleftharpoons \mathrm{Q}^{2-}, 2 \mathrm{Na}^{+}$. Presence of heavy biomolecules in the vicinity of the quinone group leads to a local modification of the proton and sodium apparent diffusion coefficient; therefore quinone electroactivity changes [38].

\subsection{Applications}

\subsubsection{Proteins as Probes}

Proteins are macromolecules made of $\alpha$-amino acids linked together by peptide bonds. The molecular weight is a fundamental characteristic of each protein; it is generally greater than $10,000 \mathrm{Da}(10 \mathrm{kDa})$. The typical model used in immunosensors for the study of protein/antibody interactions is the ovalbumin/anti-ovalbumin (OVA/ $\alpha \mathrm{OVA}$ ) system. We used this system as a model in our quinone-based biosensor. Poly(5-hydroxy-1,4-naphthoquinone-co-5-hydroxy-2-thioacetic acid-1,4-naphthoquinone) (poly(HNQ-co-HSNQA)), was used as both the immobilization and transduction element. OVA was grafted on this polymer and used as probe to detect $\alpha$ OVA present in solution. The immune complex was detected by recording the electrochemical signal using square wave voltammetry (SWV, Figure 5). In aqueous solution, quinones transfer two electrons and two protons in a concerted process. We assume that the presence of two pairs of peaks in PBS is due to two different types of quinones on the electrode surface: in the bulk of the polymer and at the polymer/electrolyte interface. The current decreased upon addition of $\alpha \mathrm{OVA}$, whereas no signal was observed upon addition of non-specific anti-KLH or diluted (1/50) normal serum.

Figure 5. Square wave voltammetry (SWV) obtained for poly(HNQ-co-HSNQA)-modified electrodes before ovalbumin (OVA) grafting (solid line), after OVA grafting (dashed line) and after anti-ovalbumin ( $\alpha$ OVA) complexation (dotted line). Serum dilution: 1/50 [44].

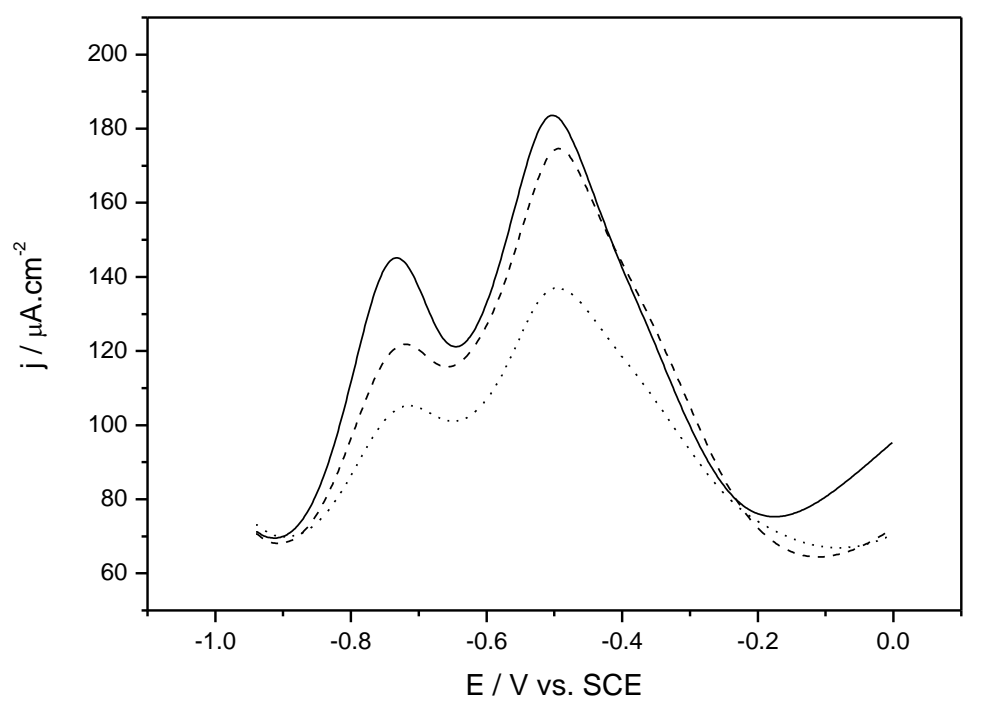

It was proposed (Figure 6(a)) that the lowering of the redox activity of the quinone groups embedded in the polymer film is due to the steric hindrance of $\alpha$ OVA (150 kDa) which is barely four times bigger than OVA (45 kDa) [44]. 
In the configuration of case a, the sensitivity of the sensor is limited by the fact that the probe (the protein) is relatively big. In terms of mean area occupied by proteins on the electrode surface, we can take the power $2 / 3$ of the molecular weight ratio to determine the relative projected area between probe and target on the electrode surface. It gives $(150 / 45)^{2 / 3}=2.2$, which means that $\alpha \mathrm{OVA}$ is only ca. two times more hindering than OVA; This is low and not optimal. One way to solve the problem is to reduce the probe size, e.g., using peptides instead of whole proteins (Figure 6(b)).

Figure 6. Transduction principle for poly(HNQ-co-HSNQA)/OVA/ $\alpha O V A$ sensor (a) case of protein/antibody complex ; (b) peptide/antibody complex.

(a)
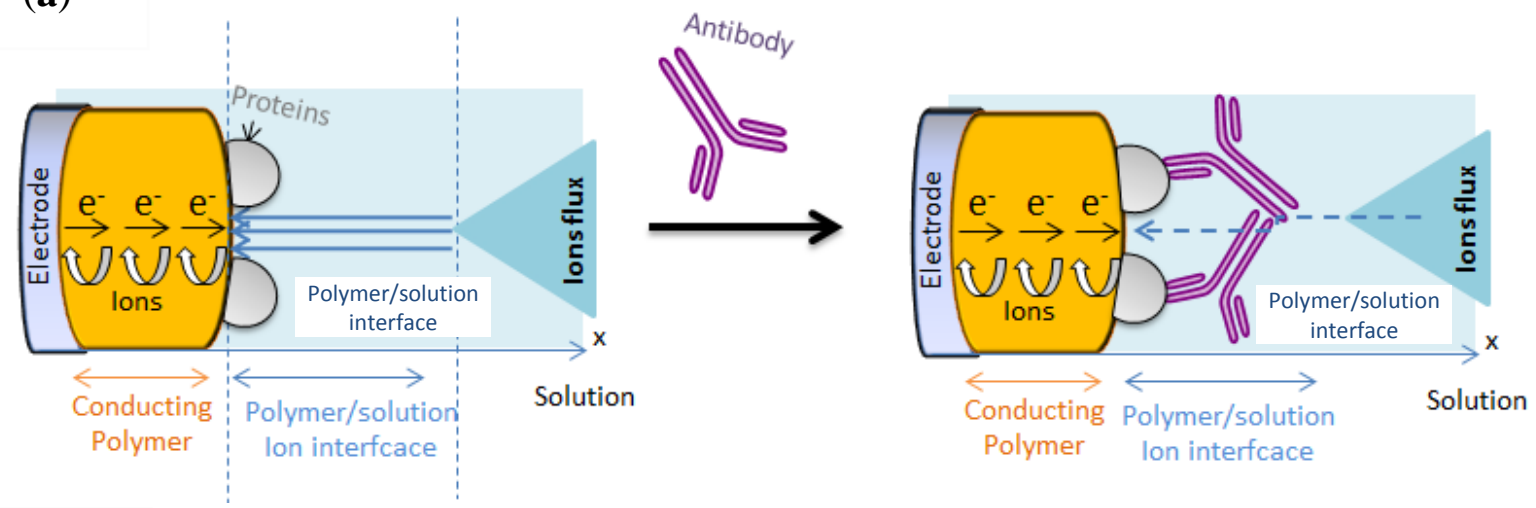

(b)
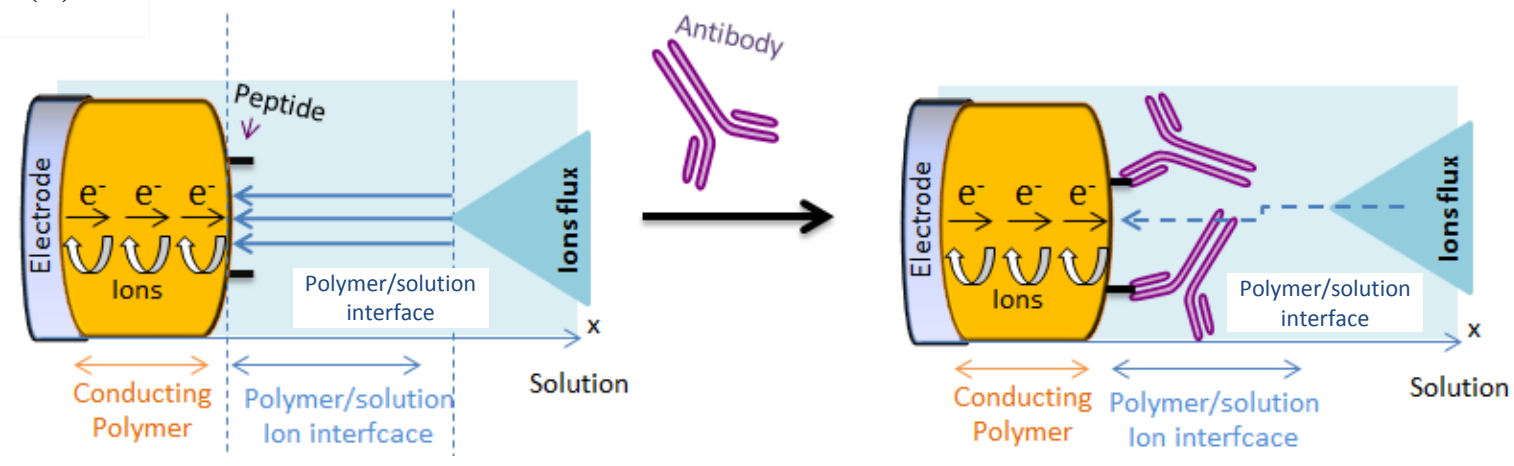

\subsubsection{Peptides for Biomolecule Grafting}

$\alpha$-Amino acids are the building blocks of proteins and peptides. They carry a primary amine group bound to the $\alpha$-carbon of the carboxylic acid group, which gives them the generic structure $\mathrm{H}_{2} \mathrm{~N}-\mathrm{CHR}-\mathrm{COOH}$ wherein $\mathrm{R}$ represents the side chain (a functional group) which identifies the $\alpha$-amino acid. Their general structure is shown in Figure 7.

The $\alpha$-Amino acids can bind to each other through an amide bond between the $\alpha$-carboxyl group of one and the $\alpha$-amine group of another, to form peptides. Compared to proteins, peptides are smaller, structurally less complex and more stable. Their synthesis can be automated, which is a considerable advantage compared to proteins and allows new biological and biomedical applications, as well as for diagnostics. Among other peptides of interest, glutathione ( $\gamma$-L-glutamyl-L-cysteinyl-glycine) is potentially an efficient linker for biomolecule immobilization on the surface. Indeed, it is a tripeptide, bearing one primary amine, two amide groups, two carboxylic groups and one thiol group, all these groups being chemically reactive (see Figure 8). 
Figure 7. General structure of $\alpha$-amino acids.

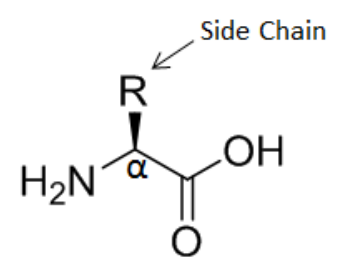

Figure 8. Structure of glutathione.<smiles>N[C@@H](CCC(=O)N[C@@H](CS)C(=O)NCC(=O)O)C(=O)O</smiles>

We recently developed direct grafting of glutathione (using the thiol group present on the side chain of cysteine) onto 5-hydroxy-1,4-naphthoquinone (HNQ) [41] to obtain 5-hydroxy-3- $\gamma$-L-glutamyl-Lcysteinyl-glycine-1,4-naphthoquinone (HNQ-Glu, Figure 9(a)) which was electropolymerized to give the polymer structure shown in Figure 9(b).

Figure 9. (a) Structure of the juglone-gluthathione conjugate (HNQ-Glu). (b) Structure of the corresponding conducting polymer poly(HNQ-Glu).
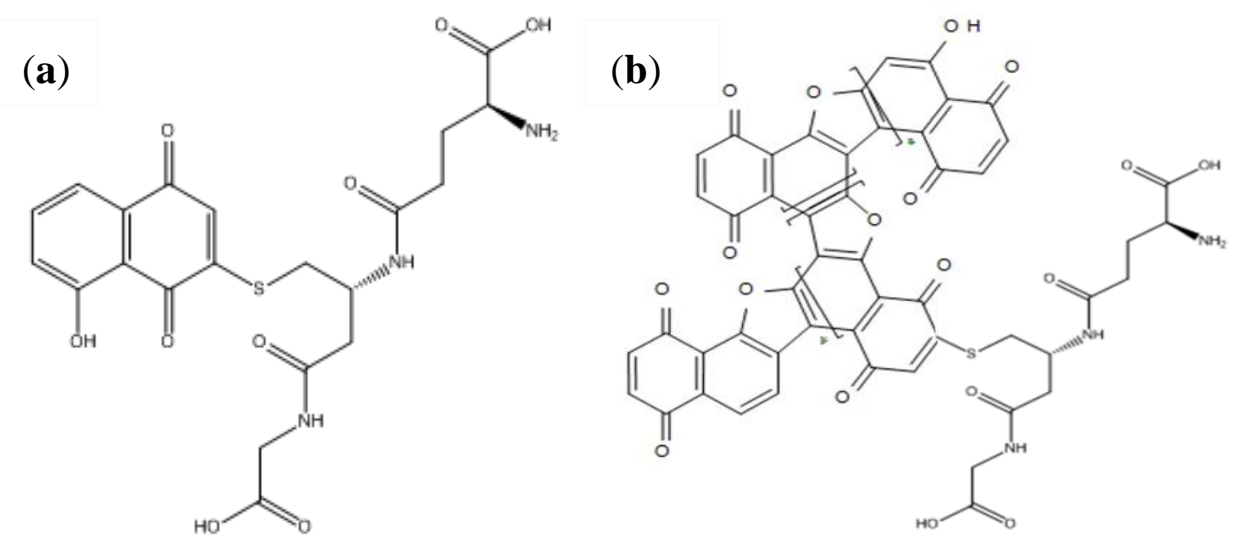

The glutathione moiety was used as the anchoring group for oligonucleotide immobilization in a DNA sensor [41].

\subsubsection{Peptides as Probes}

Protein-protein or antigen-antibody interactions involve limited areas of both partners. Activities and biological functions of proteins can be analyzed by studying the interactions between shorter synthetic peptide fragments constituting the active site of a protein and their ligands, e.g., for the study of interactions between specific peptide epitopes of a protein and its specific antibody. Following this idea, we developed a strategy for the detection of Human papillomaviruses (HPVs). 
It is known that genotypes 16 and 18 of Human papillomavirus (HPV-16 and HPV-18) are implicated in cervical cancer [50,51]. During the natural course of HPV infection, the presence of antibodies is usually observed [52]. Until now, most serological analyses have relied on enzyme-linked immunosorbent assays (ELISAs) [53] or antibody displacement assays [54]. Electrochemical biosensors for HPV detection are scarce. The most common approach consists in using immobilized antibodies which target the virus. A smarter approach consists in immobilizing a peptide present on the virus capside which can target antibodies in the infected serum [55,56]. Electrochemical detection of antibodies using peptide probes have been proposed, e.g., for the Nile virus [57]. For HPV detection, we proposed to target antibodies using HPV-16-L1 peptide (311-325 sequence, Asn-Leu-Ala-Ser-SerAsn-Tyr-Phe-Pro-Thr-Pro-Ser-Gly-Ser-Met), allowing HPV detection without labeling or adding reagent into solution. HPV-16-L1 (1,8 kDa) was grafted on the electrode to probe the HPV-16 antibody (much bigger, ca. $150 \mathrm{kDa}$ ) [42]. In this format, the big difference in size makes transduction of the molecular recognition much more sensitive than for classical ELISA-like architectures, the relative projected area between probe and target being $(150 / 1.8)^{2 / 3}=19>>2.2$ (see end of Section 2.2.1).

Figure 10. Structure of Human papillomavirus (HPV-16-L1).

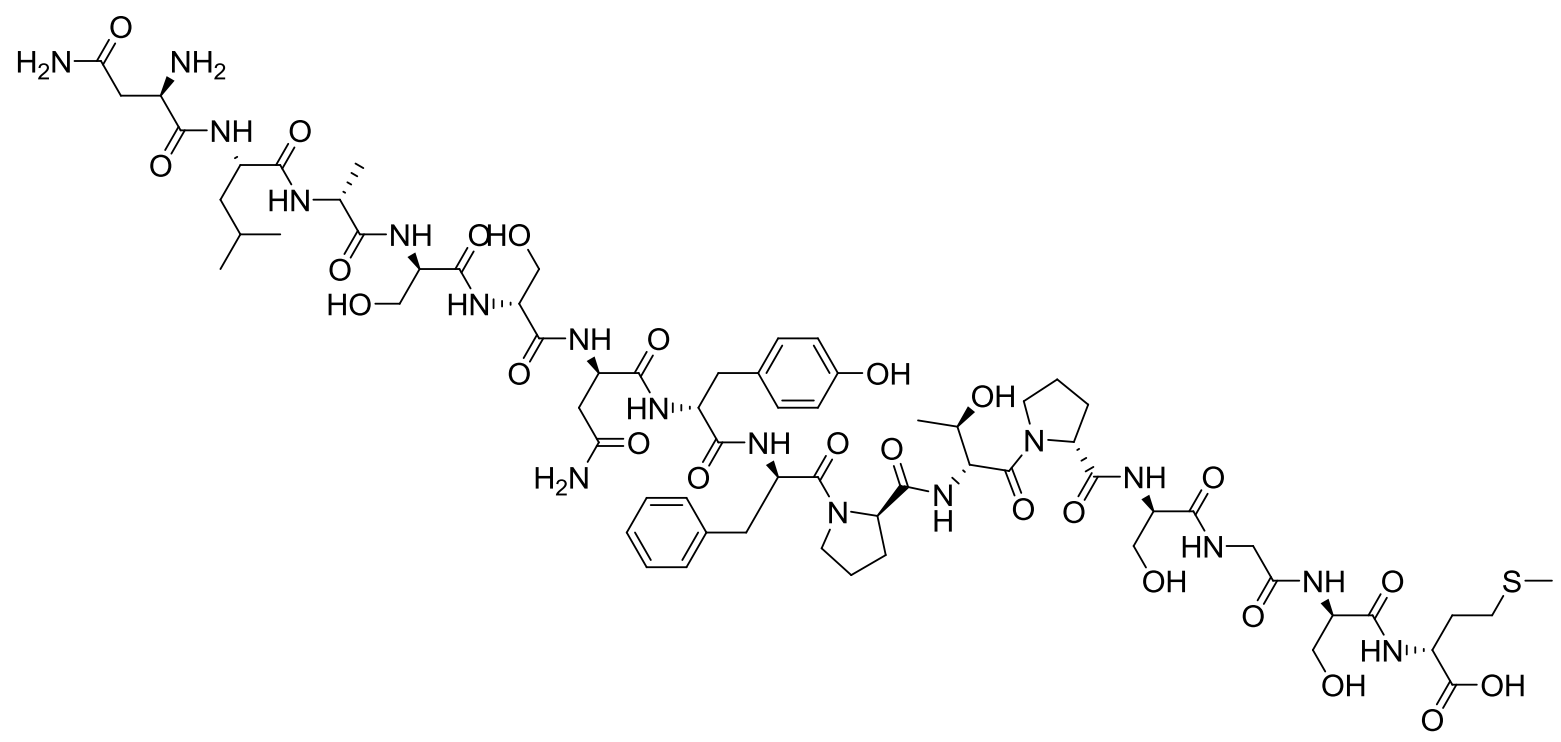

SWV was used to characterize the presence of the antibody. As expected, formation of the HPV-16-L1/anti-HPV complex induces a strong decrease in the polymer electroactivity (Figure 11(a)). If the same experiment is performed with a non-target antibody (e.g., anti-OVA), the current drop is lower than for anti-HPV (Figure 11(b)), which demonstrates the specificity of the molecular recognition.

These results were confirmed by traditional ELISA. It is important to note that due to the chemical nature of the quinone group and its redox process (the film being neutral or negatively charged, but never positively charged), poly(HNQ-co-HSNQA) enables the avoidance of non-specific adsorption of proteins on its surface (Figure 12) and therefore avoids false positives.

This work demonstrates the interest in replacing the heavy Ag probe (in this case, HPV virus) by much smaller fragments such as an oligopeptide constituted of 10 to 20 amino acids, which presents a much smaller size than a bulky (and dangerous to handle) virus. 
Figure 11. (a) SWV of a poly(HNQ-co-HSNQA) recorded in PBS before grafting (curve a), after grafting of $5 \times 10^{-8} \mathrm{M} \mathrm{HPV}-16-\mathrm{L} 1$ (curve b) and after complexation with $5 \times 10^{-8} \mathrm{M}$ $\alpha$-HPV (curve c). (b) SWV of a poly(HNQ-co-HSNQA) recorded in PBS before grafting (curve a), after grafting of $5 \times 10^{-8} \mathrm{M}$ HPV-16-L1 (curve b) and after complexation with $5 \times 10^{-8} \mathrm{M} \alpha$-OVA (curve c) [42].

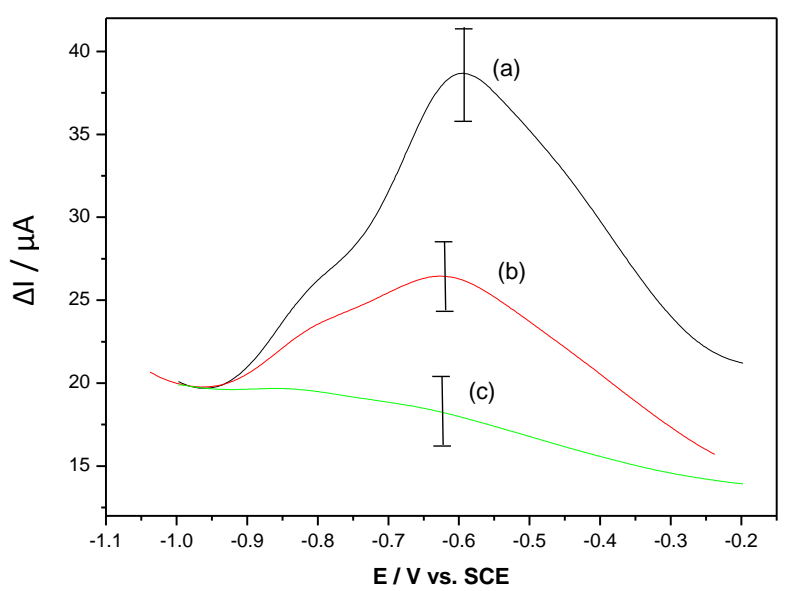

(a)

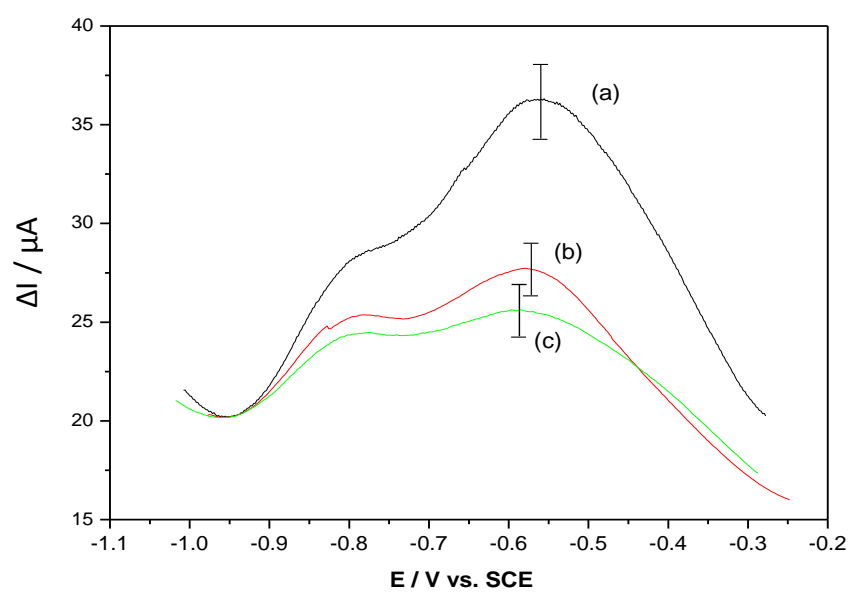

(b)

Figure 12. Absorbance obtained for spectrophotometric ELISA assays corresponding to: (1), HPV-16-L1 grafted, $+\alpha$ HPV (left bar) or $+\alpha$ OVA (right bar). (2) OVA grafted, $+\alpha$ OVA (left bar) or $+\alpha \mathrm{HPV}$ (right bar). (3) HPV grafted + no antibody (pure PBS) (left bar), or nothing grafted $+\alpha H P V$ (right bar) [42].

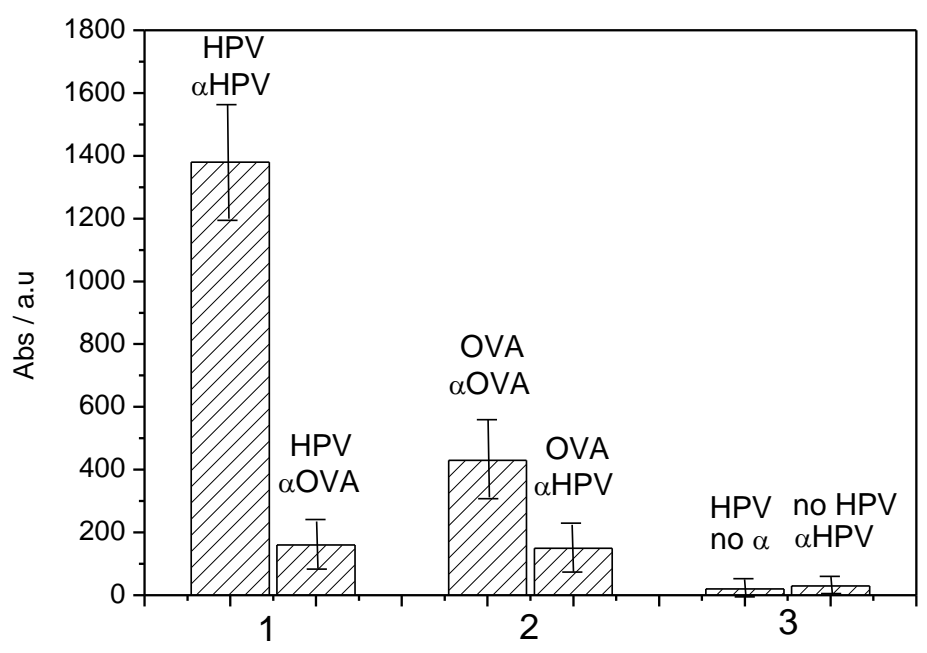

\subsubsection{Small Organic Molecules as Probes}

Analysis of potable water is correlated with public health and its regulation is under development. More than 10,000 molecules are liable to be regulated within the forthcoming years. For metrology of micro-pollutants in water (for trace quantities of the order of micrograms per liter), analyses are currently mainly achieved through chromatographic techniques coupled to mass spectrometry. However, to gain time and cost we must avoid the separation step. To keep specificity without separation, antibodies are particularly efficient and have already been used, e.g., to detect 
pesticides [58,59]. For this application, most of the label-free immunosensors described in the literature rely on a transduction format based on impedance [60,61] or amperometry [62] using a redox label. However, it has been shown that the introduction of appropriate functionalities through chemical modification of the sensor surface can provide good sensing abilities without the help of a label [18].

Atrazine (6-chloro- $N$-ethyl- $N$-[1-methylethyl]-1,3,5-triazine-2,4-diamine; ATZ) is a widely used pesticide that constitutes an excellent model for small organic pollutants for which antibodies exist. One of the most recent and pertinent examples has been reported by Cosnier et al. [63] who have shown that it is possible to detect $10 \mathrm{pg} \cdot \mathrm{mL}^{-1}$ atrazine by Electrochemical Impedance Spectroscopy (EIS) using an immunosensor based on polypyrrole film $\mathrm{N}$-substituted by nitrilotriacetic acid electrogenerated on gold electrodes. An excellent overview of detection systems for atrazine is given in [64].

It is noteworthy to recall the ability of an antibody to react with more than one antigen. This is known as cross-reactivity and arises because the cross-reacting antigen shares a structure similar to that of the immunizing antigen used to generate antibodies. We used this ability to develop a novel approach and applied this to atrazine (ATZ) detection. It is based on the competitive complexation between the anti-atrazine ( $\alpha \mathrm{ATZ}$ ) antibody on one side and atrazine present in the analyzed sample or hydroxyatrazine (HATZ) immobilized on the sensor surface on the other side, in a true direct and label-free format (no redox probe added in solution). In this particular case, the antibody $\alpha$ ATZ generated from ATZ can also bind to HATZ (the hydroxylated atrazine), but with lower affinity [65-67].

We recently developed $[47,68]$ an electrogenerated polyquinone film functionalized by a hydroxyatrazine moiety, N-(6-(4-hydroxy-6-isopropylamino-1,3,5-triazin-2-ylamino)hexyl)-5-hydroxy1,4-naphthoquinone-3-propionamide (JUG-HATZ), which contains three functional groups: the hydroxyl group for subsequent electropolymerization, the quinone group to be used as redox transducer and hydroxyatrazine as bioreceptor element (Figure 13).

Figure 13. JUG-HATZ structure.

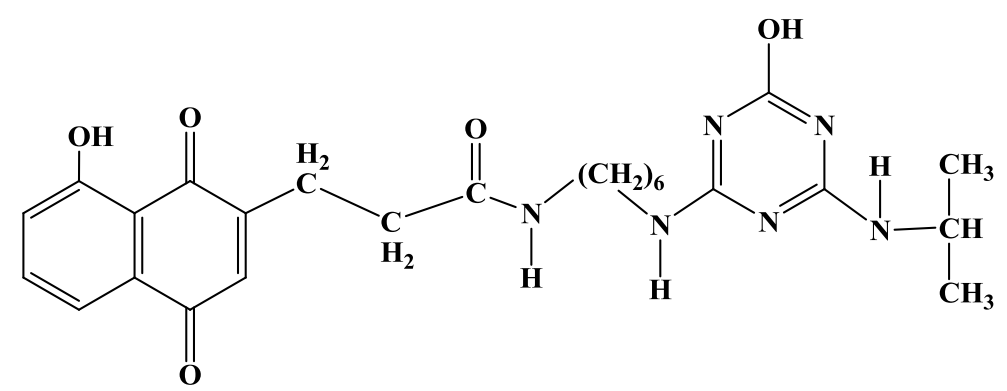

After formation of the HATZ/ $\alpha$ ATZ complex, the faradic current of the quinone group decreases (Figure 14, step 2). The electrode modified by poly(JUG-HATZ) where $\alpha$ ATZ is complexed is then utilized to detect ATZ in solution. Indeed, $\alpha$ ATZ preferentially binds to ATZ, so that a displacement equilibrium occurs (Figure 14, step 3) between ATZ in solution and HATZ incorporated in the polymer. Addition of free atrazine removes the complexed antibodies from the electrode surface leading to an increase in electroactivity. It is proposed that the removal of the $\alpha \mathrm{ATZ}$ enhances the ionic flux through the interface and leads to this current increase. Here, the relative projected area between probe and target is $(150 / 0.3)^{2 / 3}=63$, even higher than for peptide probes (see Section 2.2.3), which may explain the high sensitivity of this architecture. 
Figure 14. Immunosensor principle based on the cross-reactivity of an antibody. Example of atrazine (ATZ) detection [47].

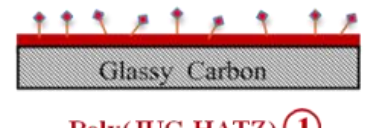

Poly(JUG-HATZ) (1)

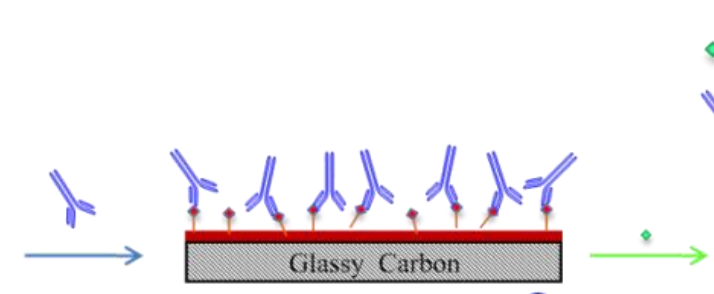

Poly(JUG-HATZ/ $\alpha$-ATZ) (2)

Atrazine
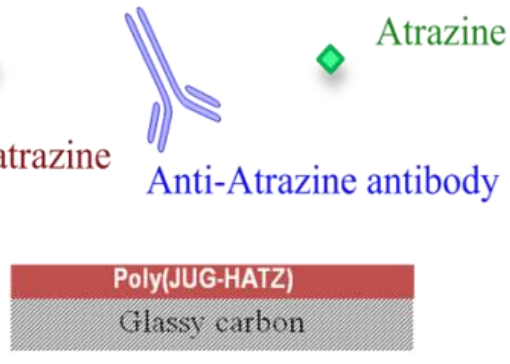

(ilassy carbon
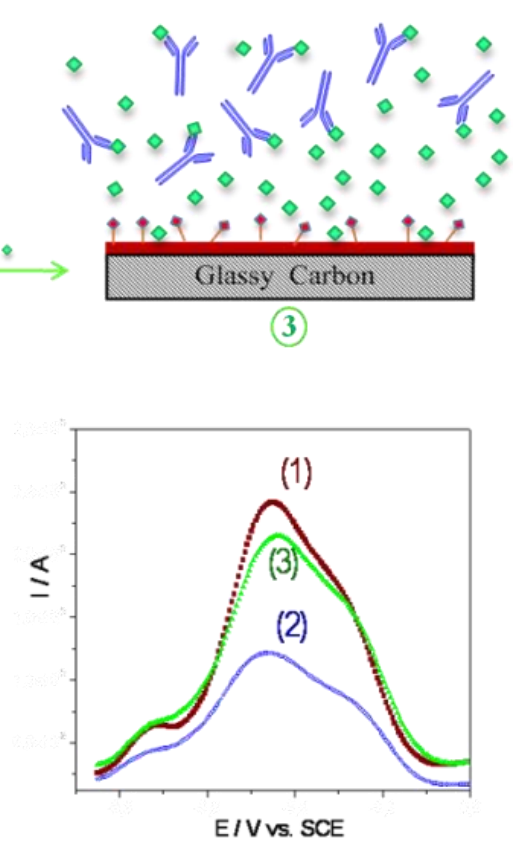

This signal-on system allows detection of one of the lowest atrazine concentrations (1 pM) reported in the literature for this kind of reagentless and label-free electrochemical immunosensor (Figure 15).

Figure 15. Percentage of $\Delta \mathrm{I} / \mathrm{I}$ measured by $\mathrm{SWV}$ at $-0.45 / \mathrm{SCE}$, after addition of ATZ for concentrations from $1 \mathrm{pM}$ up to $10 \mu \mathrm{M} . \Delta \mathrm{I}=\mathrm{I}_{\text {poly(JUG-HATZ) }}-\mathrm{I}_{\text {poly(JUG-HATZ/a-ATZ) }}$ and $\mathrm{I}=\mathrm{I}_{\text {poly }(\mathrm{JUG}-\mathrm{HATZ} / \alpha-\mathrm{ATZ})}[\mathrm{47]}$.

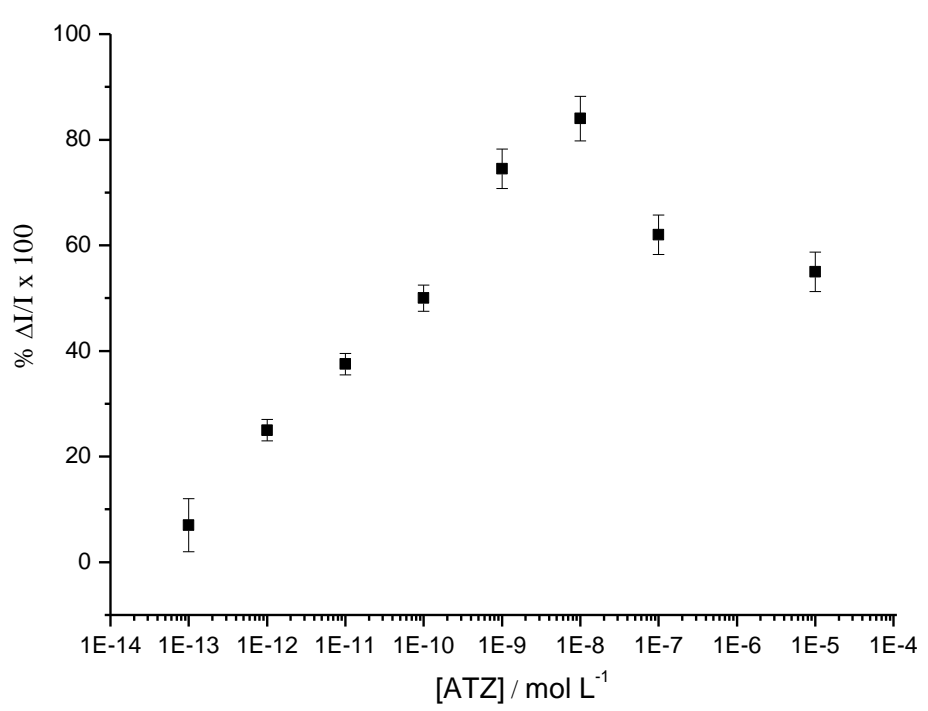

Similar experiments were performed using electrochemical impedance spectroscopy (EIS). The process allows to detect atrazine with low detection limit $\left(0.2 \mathrm{ng} \cdot \mathrm{L}^{-1}\right)$ in a true label-free format (no redox probe added in solution) by following changes in the electrochemical impedance of the sensor. $\alpha$ ATZ has a molecular weight of ca. $150 \mathrm{kDa}$ and an hydrodynamic volume of about $25 \mathrm{~nm}^{3}$, which makes a projected surface of $25^{2 / 3}=8.5 \mathrm{~nm}^{2}$. These dimensions are able to significantly 
decrease the electrolyte-film interface capacitance. On the contrary, when the antibody is removed, $C P E_{e f}$ increases, as illustrated by the results shown on Figure 16.

Figure 16. $C P E_{e f}$ as a function of $\mathrm{ATZ}$ concentration, from electrochemical impedance spectroscopy (EIS) experiments, on a poly(JUG-HATZ/ $\alpha$-ATZ)-modified electrode. Results obtained for an offset potential of $-0.5 \mathrm{~V} v s$. SCE [68].

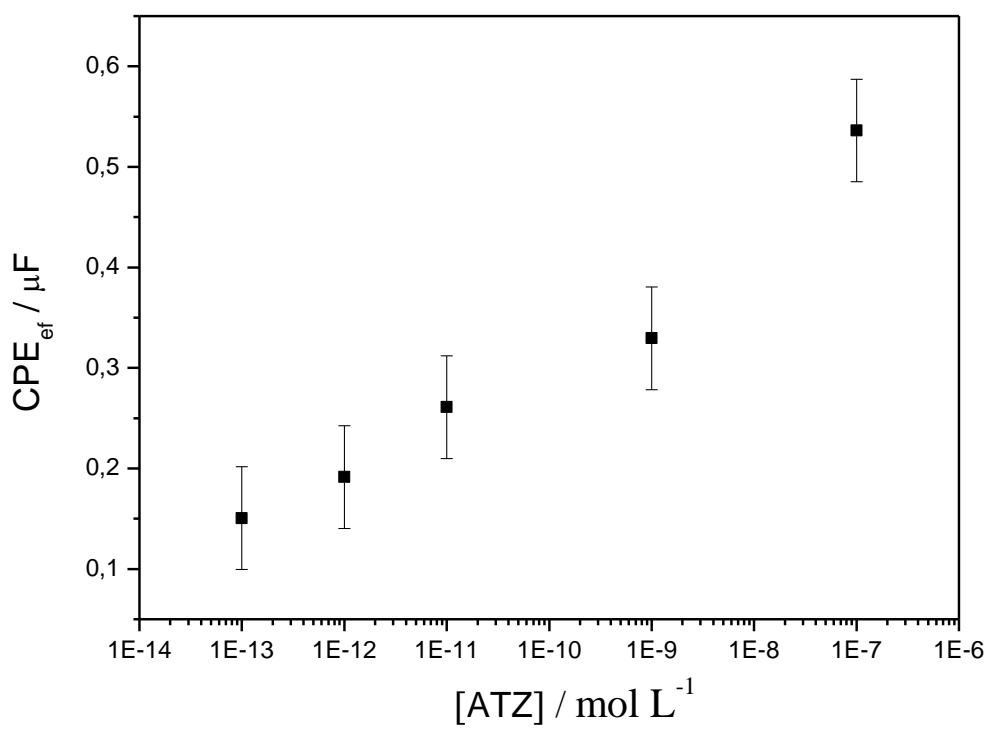

The limit of detection can be estimated at $10^{-12} \mathrm{M}$, ca. $0.2 \mathrm{ng} \cdot \mathrm{L}^{-1}$. Variations are relatively linear (on a $\log$ scale) up to $10^{-7} \mathrm{M}$ (ca. $20 \mu \mathrm{g} \cdot \mathrm{L}^{-1}$ ), which covers concentrations found in real ground water samples.

This approach is versatile: it can be extended to numerous other targets (pesticides, organic pollutants or toxins) providing they are antigenic. Work is in progress with such molecules, e.g., bisphenol A, ochratoxin A, isoproturon and glyphosates.

\section{Conclusions}

The possibility to detect very small amounts of proteins, peptides or pollutants using a cheap technique offers numerous opportunities for point-of-care diagnostics and on-site monitoring. Electrochemical devices transform the analyte capture into an electrical signal and benefit from the expertise developed in the context of microelectronics. This allows consideration of mass production and miniaturization at low cost. The vast majority of existing systems are based on indirect detection by amperometry and need either to label targets by a redox molecule or an enzyme, or to add a redox marker in solution. The need to add a reagent is a drawback which was recently bypassed by the development of direct, reagentless and label-free methods, either using amperometry or impedance. The use of electroactive layers immobilized on electrodes, e.g., ECPs, is promising. As these direct methods are mainly based on steric effects, special attention must be paid to the probe and target dimensions. Typical ELISA-based methods, for which the probe is bigger than the target, are not ideal. It is therefore crucial to decrease the probe size, using Fab' $_{2}$ antibodies, light proteins or even peptides and small haptens. 


\section{Acknowledgments}

The authors thank University Paris Diderot-Sorbonne Paris Cité and CNRS for financial support.

\section{References}

1. Sparreboom, A.; Rongen, H.A.H.; van Bennekom, W.P. Assays for interferons and interleukins in biological matrices. Anal. Chim. Acta 1994, 295, 1-26.

2. Rongen, H.A.H.; Hoetelmans, R.M.W.; Bult, A.; van Bennekom, W.P. Chemiluminescence and Immunoassays. J. Pharm. Biomed. Appl. 1994, 12, 433-462.

3. Gosling, J.P. Enzyme immunoassay. Immunoassay 1996, 287-308.

4. Gosling, J.P. Enzyme immunoassay: With and without separation. In Principles and Practice of Immunoassay, 2nd ed.; Price, C.P., Newman, D.J., Eds.; Stockton Press: London, UK, 1997; pp. 349, 351-388.

5. Porstmann, T.; Kiessig, S.T. Enzyme immunoassay techniques. J. Immunol. Methods 1992, 150, $5-21$.

6. Tijssen, P. Principles of immunoassays. Enzymes. Methods Immunol. Anal. 1993, 1, 283-297.

7. Wegner, G.J.; Lee, H.J.; Corn, R.M. Characterization and optimization of peptide arrays for the study of epitope-antibody interactions using surface plasmon resonance imaging. Anal. Chem. 2002, 74, 5161-5168.

8. Kanda, V.; Kariuki, J.K.; Harrison, D.J.; McDermott, M.T. Label-free reading of microarray-based immunoassays with surface plasmon resonance imaging. Anal. Chem. 2004, 76, 7257-7262.

9. Bizet, K.; Gabrielli, C.; Perrot, H.; Therasse, J. Validation of antibody-based recognition by piezoelectric transducers through electroacoustic admittance analysis. Biosens. Bioelectron. 1998, 13, 259-269.

10. Jones, V.W.; Kenseth, J.R.; Porter, M.D.; Mosher, C.L.; Henderson, E. Microminiaturized immunoassays using atomic force microscopy and compositionally patterned antigen arrays. Anal. Chem. 1998, 70, 1233-1241.

11. Jaffrezic-Renault, N.; Martelet, C. Preparation of well-engineered thin molecular layers on semiconductor-based transducers. Sens. Actuator. A 1992, 32, 307-312.

12. Lin, P.; Yan, F. Organic thin-film transistors for chemical and biological sensing. Adv. Mater. 2012, 24, 34-51.

13. Skládal, P. Advances in electrochemical immunosensors. Electroanalysis 1997, 9, 737-745.

14. Prodromidis, M.I. Impedimetric immunosensors-A review. Electrochim. Acta 2010, 55, 4227-4233.

15. Sargent, A.; Sadik, O.A. Monitoring antibody-antigen reactions at conducting polymer-based immunosensors using impedance spectroscopy. Electrochim. Acta 1999, 44, 4667-4675.

16. Cosnier, S. Biomolecule immobilization on electrode surfaces by entrapment or attachment to electrochemically polymerized films. A review. Biosens. Bioelectron. 1999, 14, 443-456.

17. Gerard, M.; Chaubey, A.; Malhotra, B.D. Application of conducting polymers to biosensors. Biosens. Bioelectron. 2002, 17, 345-359. 
18. Cosnier, S. Biosensors based on electropolymerized films: New trends, Anal. Bioanal. Chem. 2003, 377, 507-520.

19. Cosnier, S. Affinity biosensors based on electropolymerized films. Electroanalysis 2005, 17, 1701-1715.

20. Ionescu, R.E.; Gondran, C.; Bouffier, L.; Jaffresic-Renault, N.; Martelet, C.; Cosnier, S. Label-free impedimetric immunosensor for sensitive detection of atrazine. Electrochim. Acta 2010, 55, 6228-6232.

21. Ramanavičius, A.; Ramanavičienè, A.; Malinauskas, A. Electrochemical sensors based on conducting polymer-Polypyrrole. Electrochim. Acta 2006, 51, 6025-6037.

22. John, R.; Spencer, M.; Wallace, G.G.; Smyth, M.R. Development of a polypyrrole-based human serum albumin sensor. Anal. Chim. Acta 1991, 249, 381-385.

23. Sadik, O.A.; Wallace, G.G. Pulsed amperometric detection of proteins using antibody containing conducting polymers. Anal. Chim. Acta 1993, 279, 209-212.

24. Lu, W.; Zhao, H.; Wallace, G.G. Pulsed electrochemical detection of proteins using conducting polymer based sensors. Anal. Chim. Acta 1995, 315, 27-33.

25. Sadik, O.A.; van Emon, J.M. Designing immunosensors for environmental monitoring. Chemtech 1997, 27, 38-46.

26. Brender, S.; Sadik, O.A.; van Emon, J.M. Direct electrochemical immunosensor for polychlorinated biphenyls. Environ. Sci. Technol. 1998, 32, 788-797.

27. Sadik, O.A. Bioaffinity sensors based on conducting polymers: A short review. Electroanalysis 1999, 11, 839-844.

28. Xu, H.; Masila, M.; Yan, F.; Sadik, O.A. Multiarray sensors for pesticides and toxic metals. Proc. SPIE 1999, 3534, 437-445.

29. Rahman, M.A.; Shiddiky, M.J.A.; Park, J.-S.; Shim, Y.-B. An impedimetric immunosensor for the label-free detection of bisphenol A. Biosens. Bioelectron. 2007, 22, 2464-2470.

30. Khan, R.; Dhayal, M. Chitosan/polyaniline hybrid conducting biopolymer base impedimetric immunosensor to detect Ochratoxin-A. Biosens. Bioelectron. 2009, 24, 1700-1705.

31. Lacaze, P.C.; Pham, M.C.; Delamar, M.; Dubois, J.E. Extension of the voltammetric theory to inert, permeable thin-film coated rotating-disk electrodes. Behavior of ferrocene-ferricinium ion and quinone-hydroquinone systems on polymer-coated electrodes. J. Electroanal. Chem. 1980, 108, 9-16.

32. Leidner, C.R.; Gater, V.K. Ion and electron-transport within amino-quinone polymer-films. J. Electrochem. Soc. 1987, 134, C502.

33. Gater, V.K.; Love, M.D.; Liu, M.D.; Leidner, C.R. Quinone molecular films derived from 1,5-diaminoanthraquinone. J. Electronanal. Chem. 1987, 235, 381-385.

34. Gater, V.K.; Liu, M.D.; Love, M.D.; Leidner, C.R. Quinone molecular films derived from aminoquinones. J. Electroanal. Chem. 1988, 257, 133-146.

35. Miller, L.L.; Zinger, B.; Degrand, C. The effects of cross-linking and anodic surface roughening on quinone polymer carbon electrodes. J. Electroanal. Chem. 1984, 178, 87-99.

36. Pham, M.C.; Piro, B.; Bazzaoui, E.A.; Hedayatullah, M.; Lacroix, J.C.; Novak, P.; Haas, O. Anodic oxidation of 5-amino-1,4-naphthoquinone (ANQ) and synthesis of a conducting polymer (PANQ). Synth. Met. 1998, 92, 197-205. 
37. Haringer, D.; Novak, P.; Haas, O.; Piro, B.; Pham, M.C. Poly(5-amino-1,4-naphthoquinone), a novel lithium-inserting electroactive polymer with high specific charge. J. Electrochem. Soc. 1999, 146, 2393-2396.

38. Reisberg, S.; Piro, B.; Noel, V.; Pham, M.C. Selectivity and sensitivity of a reagentless electrochemical DNA sensor studied by square wave voltammetry and fluorescence. Bioelectrochemistry 2006, 69, 172-179.

39. Piro, B.; Reisberg, S.; Noel, V.; Pham, M.C. Investigations of the steric effect on electrochemical transduction in a quinone-based DNA sensor. Biosens. Bioelectron. 2007, 22, 3126-3131.

40. Piro, B.; Haccoun, J.; Pham, M.C.; Tran, L.D.; Rubin, A.; Perrot, H.; Gabrielli, C. Study of the DNA hybridization transduction behavior of a quinone-containing electroactive polymer by cyclic voltammetry and electrochemical impedance spectroscopy. J. Electroanal. Chem. 2005, 577, $155-165$.

41. Reisberg, S.; Acevedo, D.F.; Korovitch, A.; Piro, B.; Noel, V.; Buchet, I.; Tran, L.D.; Barbero, C.A.; Pham, M.C. Design of a new electrogenerated polyquinone film substituted with glutathione. Towards direct electrochemical biosensors. Talanta 2010, 80, 1318-1325.

42. Piro, B.; Kapella, A.; Le, V.H.; Anquetin, G.; Zhang, Q.D.; Reisberg, S.; Noel, V.; Tran, L.D.; Duc, H.T.; Pham, M.C. Towards the detection of human papillomavirus infection by a reagentless electrochemical peptide biosensor. Electrochim. Acta 2011, 56, 10688-10693.

43. Zhang, Q.D.; March, G.; Noel, V.; Piro, B.; Reisberg, S.; Tran, L.D.; Hai, L.V.; Abadia, E.; Nielsen, P.E.; Sola, C.; Pham, M.C. Label-free and reagentless electrochemical detection of PCR fragments using self-assembled quinone derivative monolayer: Application to Mycobacterium tuberculosis. Biosens. Bioelectron. 2012, 32, 163-168.

44. Piro, B.; Zhang, Q.D.; Reisberg, S.; Noel, V.; Dang, L.A.; Duc, H.T.; Pham, M.C. Direct and rapid electrochemical immunosensing system based on a conducting polymer. Talanta, 2010, 82, 608-612.

45. Piro, B.; Reisberg, S.; Noel, V.; Pham, M.C. Investigations of the steric effect on electrochemical transduction in a quinone-based DNA sensor. Biosens. Bioelectron. 2007, 12, 3126-3131.

46. Reisberg, S.; Piro, B.; Noel, V.; Nguyen, T.D.; Nielsen, P.E.; Pham, M.C. Investigation of the charge effect on the electrochemical transduction in a quinone-based DNA sensor. Electrochim. Acta 2008, 54, 346-351.

47. Tran, H.V.; Yougnia, R.; Reisberg, S.; Piro, B.; Serradji, N.; Nguyen, T.D.; Tran, L.D.; Dong, C.Z.; Pham, M.C. A label-free electrochemical immunosensor for direct, signal-on and sensitive pesticide detection. Biosens. Bioelectron. 2012, 31, 62-68.

48. Sassolas, A.; Prieto-Simón, B.; Marty, J. Biosensors for pesticide detection: New trends. Am. J. Anal. Chem. 2012, 3, 210-232.

49. Thomson, R.H. Studies in the juglone series. 3. Addition reactions. J. Org. Chem. 1951, 16, 1082-1090.

50. Bosch, F.X.; Manos, M.M.; Munoz, N.; Sherman, M.; Jansen, A.M.; Peto, J.; Schiffman, M.H.; Moreno, V.; Kurman, R.; Shan, K.V. Prevalence of human papillomavirus in cervical-cancerA worldwide perspective. J. Nat. Cancer. Inst. 1995, 87, 796-802. 
51. Munoz, N.; Bosch, F.X.; De Sanjose, S.; Herrero, R.; Castellsague, X.; Shah, K.V.; Snijders, P.J.F.; Meijer, C.J.L.M. Epidemiologic classification of human papillomavirus types associated with cervical cancer. New Engl. J. Med. 2003, 348, 518-527.

52. Tyring, S.K. Human papillomavirus infections: Epidemiology, pathogenesis, and host immune response. J. Am. Acad. Dermatol. 2000, 43, S18-S26.

53. Dillner, J. The serological response to papillomaviruses. Semin. Cancer Biol. 1999, 9, 423-430.

54. Yeager, M.D.; Aste-Amezaga, M.; Brown, D.R.; Martin, M.M.; Shah, M.J.; Cook, J.C.; Christensen, N.D.; Ackerson, C.; Lowe, R.S.; Smith, J.F.; Keller, P.; Jansen, K.U. Neutralization of human papillomavirus (HPV) pseudovirions: A novel and efficient approach to detect and characterize HPV neutralizing antibodies. Virology 2000, 278, 570-577.

55. Caygill, R.L.; Blair, G.E.; Millner, P.A. A review on viral biosensors to detect human pathogens. Anal. Chim. Acta 2010, 681, 8-15.

56. Caygill, R.L.; Hodges, C.S.; Holmes, J.L.; Higson, S.P.J.; Blair, G.E.; Millner, P.A. Novel impedimetric immunosensor for the detection and quantitation of Adenovirus using reduced antibody fragments immobilized onto a conducting copolymer surface. Biosens. Bioelectron. 2012, 32, 104-110.

57. Ionescu, R.E.; Cosnier, S.; Herrmann, S.; Marks, R.S. Amperometric immunosensor for the detection of anti-West Nile virus IgG. Anal. Chem. 2007, 79, 8662-8668.

58. Marty, J.L.; Garcia, D.; Rouillon, R. Biosensors-Potential in pesticide detection. Trends Anal. Chem. 1995, 14, 329-333.

59. Dennison, M.J.; Turner, A.P.F. Biosensors for environmental monitoring. Biotechnol. Adv. 1995, $13,1-12$.

60. Hleli, S.; Martelet, C.; Abdelghani, A.; Burais, N.; Jaffrezic-Renault, N. Atrazine analysis using an impedimetric immunosensor based on mixed biotinylated self-assembled monolayer. Sens. Actuator. B 2006, 113, 711-717.

61. Valera, E.; Ramón-Azcón, J.; Barranco, A.; Alfaro, B.; Sánchez-Baeza, F.; Marco, M.-P.; Rodríguez, Á. Determination of atrazine residues in red wine samples. A conductimetric solution. Food Chem. 2010, 122, 888-894.

62. Besombes, J.L.; Cosnier, S.; Labbé, P.; Reverdy, G. A biosensor as warning device for the detection of cyanide, chlorophenols, atrazine and carbamate pesticides. Anal. Chim. Acta 1995, $311,255-263$.

63. Ionescu, R.E.; Gondran, C.; Bouffier, L.; Jaffrezic-Renault, N.; Martelet, C.; Cosnier, S. Label-free impedimetric immunosensor for sensitive detection of atrazine. Electrochim. Acta 2010, 55, 6228-6232.

64. Ballesteros-Gomez, A.; Rubio, S. Recent advances in environmental analysis. Anal. Chem. 2011, 83, 4579-4613.

65. Schlaeppi, J.M.; Foery, W.; Ramsteiner, K. Hydroxyatrazine and atrazine determination in soil and water by enzyme-linked immunosorbent-assay using specific monoclonal-antibodies. J. Agric. Food Chem. 1989, 37, 1532-1538.

66. Wortberg, M.; Jones, G.B.; Kreissig, S.; Rocke, D.M.; Gee, S.J.; Hammock, B.D. An approach to the construction of an immunoarray for differentiating and quantitating cross reacting analytes. Anal. Chim. Acta 1996, 319, 291-303. 
67. Charlton, K.; Harris, W.J.; Porter, A.J. The isolation of super-sensitive anti-hapten antibodies from combinatorial antibody libraries derived from sheep. Biosens. Bioelectron. 2001, 16, 639-646.

68. Tran, H.V.; Reisberg, S.; Piro, B.; Pham, M.C. Label-free electrochemical immunoaffinity sensor based on impedimetric method for pesticide detection. Electroanalysis 2013, in press.

\section{Appendx}

\section{Experimentals}

Phosphate buffer saline (PBS) had a pH of 7.4 and was provided by Sigma. Aqueous solutions were made with ultrapure $(18 \mathrm{M} \Omega \mathrm{cm})$ water. Glassy carbon electrodes $\left(\mathrm{GC}, 3 \mathrm{~mm}\right.$ in diameter, $\left.\mathrm{S}=0.07 \mathrm{~cm}^{2}\right)$ were purchased from BASInc. 5-hydroxy-1,4-naphthoquinone (JUG), 1-naphthol (1-NAP), lithium perchlorate $\left(\mathrm{LiClO}_{4}\right)$, acetonitrile $(\mathrm{ACN})$ and ethanol $(\mathrm{EtOH})$, practical grade, were from Sigma-Aldrich. Atrazine (ATZ) and atrazine-desethyl-2-hydroxy (ATD) were purchased from Supelco (USA). Anti-atrazine ( $\alpha$-ATZ) antibody (monoclonal) was purchased from Thermo Scientific, USA. A. OVA (egg albumin, $2 \times$ crystallized) was purchased from Calbiochem, La Jolla, CA, USA. HPV-16-L1 peptide (311-325 sequence, i.e., Asn-Leu-Ala-Ser-Ser-Asn-Tyr-Phe-Pro-Thr-Pro-Ser-Gly-Ser-Met) was purchased from Genscript, USA. Secondary Goat $\left.\mathrm{F}(\mathrm{ab})^{\prime}\right)_{2}$ anti-Mouse Ig conjugated to horseradish peroxidase was purchased from Tebu (Le Perray-en-Yvelines, France). Antibodies against HPV ( $\alpha$ HPV, mouse anti-papillomavirus $16 \mathrm{~L} 1$ late protein, monoclonal antibody) and against OVA ( $\alpha \mathrm{OVA})$ were obtained from AbD serotec (Morphosys, UK). The electrochemical synthesis of the polymer films was carried out by electro-oxidation of $5 \times 10^{-3} \mathrm{M}$ JUG-HATZ $+10^{-3} \mathrm{M} 1-\mathrm{NAP}+0.1 \mathrm{M} \mathrm{LiClO}_{4}$ in ACN on GC electrodes, under Ar, at a constant potential of $1.25 \mathrm{~V}$ ( vs. SCE) during $600 \mathrm{~s}$. Square wave voltammetry (SWV) was used to characterize $\alpha$-ATZ complexation and ATZ detection. The following parameters were used: pulse height $50 \mathrm{mV}$, pulse width $50 \mathrm{~ms}$, scan increment $2 \mathrm{mV}$, frequency 12.5 Hz. EIS was performed using an Autolab PGSTAT30 equipped with the FRA module. Impedance spectra were recorded in PBS buffer at room temperature at a given offset potential within a frequency range from $10 \mathrm{kHz}$ to $100 \mathrm{mHz}$ with a perturbation amplitude of $10 \mathrm{mV}$. As a pretreatment before each experiment, a constant potential corresponding to the one used for EIS was imposed, for $120 \mathrm{~s}$. Solutions were systematically deaerated with Ar before and during experiments.

(C) 2013 by the authors; licensee MDPI, Basel, Switzerland. This article is an open access article distributed under the terms and conditions of the Creative Commons Attribution license (http://creativecommons.org/licenses/by/3.0/). 